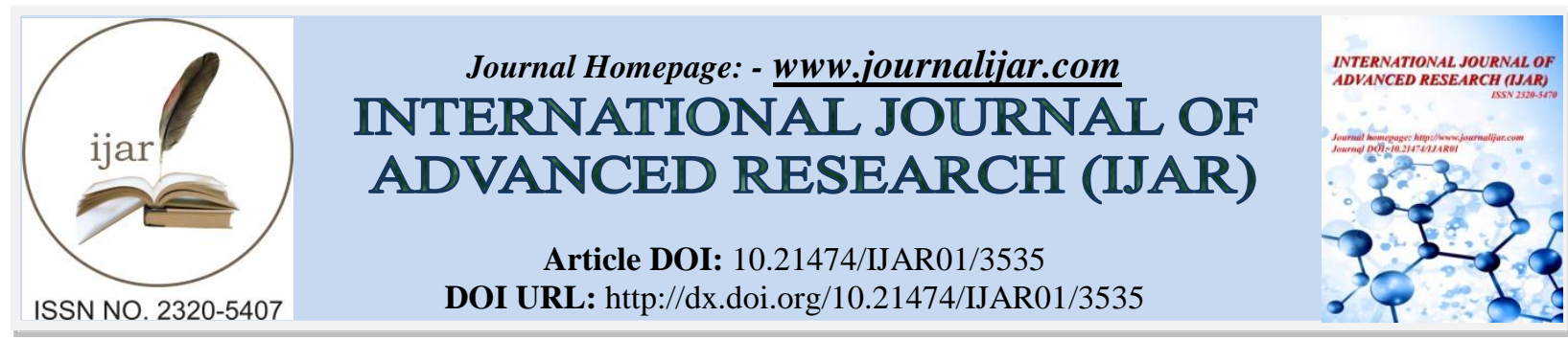

RESEARCH ARTICLE

\title{
ANALYSIS OF METEOROLOGICAL DROUGHT IN IRAQ USING THE RECONNAISSANCE DROUGHT INDEX (RDI).
}

Omar M. A. Mahmood Agha ${ }^{1,3}$ and Nermin. Şarlak ${ }^{2}$.

1. Department of Dams and Water Resources Engineering, Mosul University, Mosul, Iraq.

2. Department of Civil Engineering, Karamanoglu Mehmetbey University, Karaman, Turkey.

3. Department of Civil Engineering, Gaziantep University, Gaziantep, Turkey.

\section{Manuscript Info}

\section{Manuscript History}

Received: 13 January 2017

Final Accepted: 15 February 2017

Published: March 2017

Key words:-

Reconnaissance Drought Index (RDI); Drought; Iraq.

\begin{abstract}
The drought characteristics were analyzed in Iraq dependent on the observed climate data from ten meteorological stations during 19802011. Reconnaissance Drought Index (RDI) was used to studying and analyzing of droughts. The variable of interest in RDI is precipitation over potential evapotranspiration (ETo), the ETo is calculated using Penman-Monteith method. The results showed that the 2008 year was the worst dry year had passed in all parts of Iraq. It was observed that the maximum severity of drought (Smax) was identified during the periods (2007-2009) for the most stations. The Mild drought (Extremely drought) conditions are the highest (lowest) number of drought event than other conditions for all stations. Most of study region experienced the strongest drought events through the last period from 1999 to 2009 as compared with the previous period.
\end{abstract}

Copy Right, IJAR, 2017,. All rights reserved.

\section{Introduction:-}

In the last decades, drought has become a frequent phenomenon in many parts of the world, which in turn affects heavily on agriculture and water sources [1]. Analysis and monitoring of drought can be done with drought indices such as the Palmer Drought Severity Index (PDSI) widely used in the United States [2], the decile index operational in Australia [3], Z-Index used by the National Metrological Center of China [4], the Standardized Precipitation Index (SPI) [5], Reconnaissance Drought Index (RDI) [6], and the Standardized Precipitation Evapotranspiration Index (SPEI) [7]. The climate of Iraq classified as dry and semi-dry, so the impact of evapotranspiration on the drought considers a significant impact. Therefore, the Reconnaissance Drought Index (RDI) was used among these indices in this study, which is based on both precipitation and potential evapotranspiration.

Several studies on drought assessment have been carried out in different parts of the world can be summarized as follows: [8] attempted an assessment and monitoring of regional drought using two well-known indices, namely, SPI and RDI, during the period 1971-2008 in Cyprus. They found that both indices had been given a similar form in analyze drought conditions and monitor drought events. [9] used the SPI to evaluate the spatial and temporal characteristics of meteorological drought for the period 1980 to 2010 in Iraq. They showed that the worst dry year was observed at $2008.30 \%, 36 \%, 22 \%$ and $12 \%$ of the area were classified under extreme, severe, moderate and near normal drought, respectively. [10] investigated the similarities or differences in SPI and RDI indices using data from a variety of climatic zones in Iran. Although their results showed that both indices had the same behavior, RDI index depends on ET was more sensitive to climatic variability than SPI index. The Iraq region is also prone to 
drought. Nevertheless, the drought condition and its characteristics in Iraq has received limited attention. [11] calculated the SPI for 12-month using rainfall data records observed from 1941 to 2002 in the north of Iraq. He found that the percentage of wet (drought) conditions were up to $44 \%(56 \%)$ of the study period. He declared that moderate wet and drought conditions were more common than others. [12] used the SPI method for 9, 12-month time scales. The results showed that the Northern of Iraq exposed to the severe drought for SPI 9- month during the study period as compared with other parts of the region. Whilst, the Baghdad, and Diwaniya regions experienced the highest degree of drought according to SPI 12-month.

The main aim of this paper is to analyze the drought characteristics using Reconnaissance Drought Index (RDI 9month) for ten stations in Iraq. A MATLAB software codes were written by M-File Programming to calculate the potential evapotranspiration and drought characteristics.

\section{Materials and Methods:-}

Study area and Meteorological data:-

Iraq region is located in southwest Asia at the crossroads of the Middle East. It covers an area of 435,052 $\mathrm{km} 2$, which lies between the latitudes of $29^{\circ} 5^{\prime}$ and $37^{\circ} 22^{\prime}$ north and the longitudes of $38^{\circ} 45^{\prime}$ and $48^{\circ} 45$ east. Historical records of monthly precipitation, temperature, humidity, wind speed, and sunshine data from 1980 to 2011 were obtained from the Iraqi Meteorological Organization and Seismology (IMOS) for ten stations. The location of the Meteorological stations are presented as shown in Fig.1.

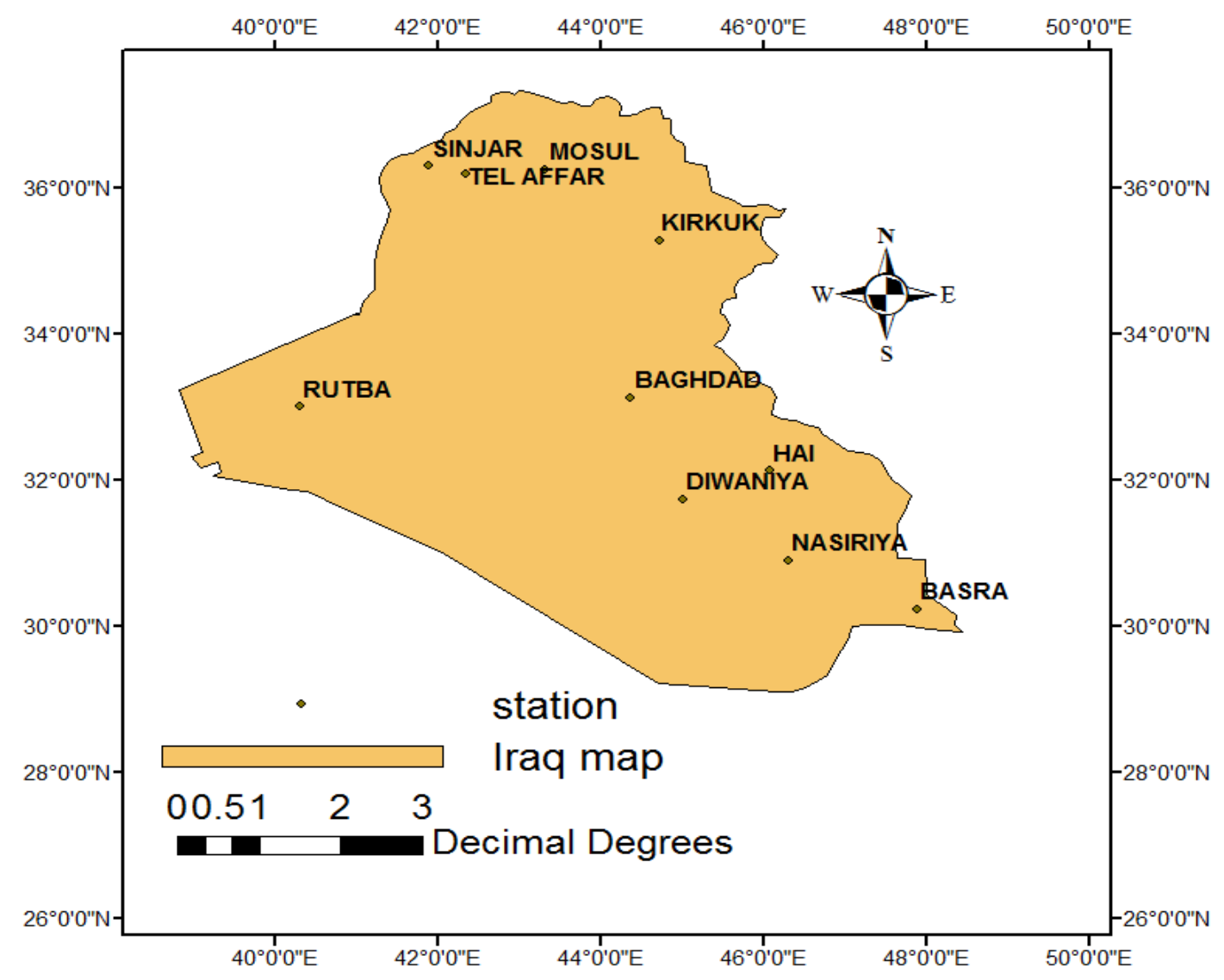

Fig.1:- locations of meteorological stations in Iraq 


\section{Methodology:-}

\section{Reconnaissance Drought Index (RDI):-}

The Reconnaissance Drought Index is based on the ratios of precipitation over potential evapotranspiration values for different time scales [13]. The potential evapotranspiration is computed by the Penman- Monteith formula. Initially, $\alpha_{\mathrm{k}}$ is presented as the coefficient of the ith year in an aggregated form using a monthly time step and can be calculated on a monthly, seasonal or annual basis as following.

$a_{k}^{(i)}=\frac{\sum_{j=1}^{k} P_{i j}}{\sum_{j=1}^{k} E T_{i j}}, \quad i=1: N \quad$ and $j=1: k$

Where $\mathrm{P}_{\mathrm{ij}}$ is precipitation, $\mathrm{ET}_{\mathrm{ij}}$ is potential evapotranspiration in $\mathrm{j}^{\text {th }}$ month of $\mathrm{i}^{\text {th }}$ year.

The next step, the Normalized RDI (RDIn) is calculated, utilizing $\bar{\alpha}_{o}$ is the arithmetic mean of $\alpha_{0}$ values calculated for the $\mathrm{N}$ years of data.

$R D I_{n}^{i}=\frac{\alpha_{o}^{i}}{\bar{\alpha}_{o}}-1$

After that, the Standardized RDI (RDIst) is calculated, using the following equation for each year.

$R D I_{s t}^{i}=\frac{y^{i}-\bar{y}}{\widehat{\sigma}_{y}}$

Where $\mathrm{y}_{\mathrm{i}}$ is the $\ln \left(\alpha_{0}{ }^{(\mathrm{i})}\right), \bar{y}$ its arithmetic mean and $\hat{\sigma}_{y}$ is its standard deviation. In this study RDI is applied to represent RDIst. Drought category classification suggested for the RDI [13] as illustrated in Table-1.

Table 1:- Drought classification for RDI value and corresponding event probabilities.

\begin{tabular}{|c|c|c|}
\hline RDI & Classification & Probability (\%) \\
\hline 0 to -0.99 & Mild drought (Mi.D) & 34.1 \\
\hline-1 to -1.49 & Moderately drought (Mo.D) & 9.2 \\
\hline-1.5 to -1.99 & Very drought (S.D) & 4.4 \\
\hline$-2<$ & Extremely drought (E.D) & 2.3 \\
\hline
\end{tabular}

Calculation of potential evapotranspiration:-

The Penman - Monteith formal is one of the most common used ones, defined as equation (4), recommended by the FAO in 1998 as reference ET, depended on observed meteorological data, such as the temperature, relative humidity, sunshine hours, and wind speed. Many studies found that the penman-monteith is more appropriate for arid and semi-arid regions [14];[15];[16]. In present study, total potential evapotranspiration (ET0) has been estimated for the study stations using Penman - Monteith equation [17] as follows

$$
E T_{\circ}=\frac{0.408 \Delta\left(R_{n}-G\right)+\gamma \frac{900}{T+273} U_{2}(e s-e a)}{\Delta+\gamma\left(1+0.34 U_{2}\right)}
$$

Where ET0 is the potential evapotranspiration rate $\left(\mathrm{mm} \mathrm{d}^{-1}\right)$, and the monthly value of ET0 will be used in this paper, $\mathrm{G}$ is the soil heat flux density ( $\mathrm{MJ} \mathrm{m}^{-2}$ day- $\left.{ }^{1}\right)$; $\mathrm{T}$ is the mean daily air temperature at $2 \mathrm{~m}$ height $\left({ }^{0} \mathrm{C}\right)$; $\mathrm{U} 2$ is the wind speed at $2 \mathrm{~m}$ height $\left(\mathrm{m} \mathrm{s}^{-1}\right)$; ed is the saturation vapor pressure $(\mathrm{KPa})$; ea is the actual vapor pressure $(\mathrm{KPa}) ; \Delta$ is slope of vapor pressure curve $(\mathrm{KPa} 0 \mathrm{C}-1) ; \gamma$ is the psychrometric constant $(\mathrm{KPa} 0 \mathrm{C}-1)$; $\mathrm{Rn}$ is the net radiation at the crop surface (MJ m-2 day-1).

\section{Results and Discussion:-}

Drought characteristics for the RDI from 1980 to 2011 periods were presented in Table-1. It can observe from this table, the value of the maximum severity of drought (Smax) was identified during the periods (2007-2009) for the most stations. The highest value of Smax was found at Kirkuk station, and had the longest duration drought, began in Jan-2007 and ended in Oct-2009, lasted 34 months. The maximum value of the severity of peak drought (Sp) was observed in BAGHDAD station, occurred in Nov-1990 and relative frequency of drought during the whole periods is $43.4 \%$. While the relative frequency (RF) for all stations ranged between $39.6 \%-52.1 \%$.

As shown in Fig.2, the longer duration of drought for Mosul was observed between Sep-1998- Jul-2002 (47months), with the intensity of 1.3. The years in 1998, 1999, 2000, 2007, 2008, and 2009 were the worst drought years as compared with other years. Baghdad (Rutba) station exposed to worst dry through the years 1986, 1987, 1997, 1999, 2007, 2008, and 2009 (1983, 1984, 2001, 2004,2005,2006 and 2007), experienced the longer duration 
of drought between Dec 1998- Jan2001 (Jan2004-Jun2005), with intensity 1(1.5). In Basra station, the longer duration of drought was determined between Jan2010- Dec2011. It exposed to worst dry years in 1994, 2003, 2008, 2010, and 2011.

Table 2:- Drought characteristics for the RDI 9-month time scale from 1980 to 2011 periods

\begin{tabular}{|c|c|c|c|c|}
\hline Station & $\begin{array}{c}\text { The severity of peak } \\
\text { drought (Sp) }\end{array}$ & $\begin{array}{c}\text { The } \\
\text { relative } \\
\text { frequencies } \\
\text { (RF)\% }\end{array}$ & $\begin{array}{c}\text { The minimum } \\
\text { severity of drought } \\
\text { (Smin) }\end{array}$ & $\begin{array}{c}\text { The maximum severity of } \\
\text { drought (Smax) }\end{array}$ \\
\hline MOSUL & $-2.65 /$ (April 2008) & 44.95 & $-0.01 /$ (May. 1997) & $-58.80 /$ (Sept. 1998 -July 2002) \\
\hline SINJAR & $-2.80 /$ (Nov. 2005) & 45.21 & $-0.001 /$ (Aug. 1986) & $-40.11 /$ (Nov. 2007 -Dec. 2009) \\
\hline TEL AFFAR & $-2.71 /$ (Oct. 2000) & 39.63 & $-0.01 /$ (Apr. 1992) & -47.73 / (Sept.1998- April 2001) \\
\hline KIRKUK & $-3.09 /$ (Nov. 1999) & 42.82 & $-0.02 /$ (Apr. 1992) & $-52.55 /$ ( Jan. 2007-Oct. 2009) \\
\hline BAGHDAD & $-3.81 /$ (Nov. 1999) & 43.35 & $-0.16 /$ (Jan. 2003) & $-35.80 /$ (Dec. 2007-Oct.2009) \\
\hline RUTBA & $-3.78 /$ (Sept. 2004) & 44.15 & $-0.01 /$ (Sept. 1986) & -28.74 / (Jan. 2004-July 2005) \\
\hline HAI & $-3.63 /$ (Dec. 2003) & 47.34 & $-0.001 /$ (Sept. 2010) & -45.31 (Jan. 2003-Dec.2004) \\
\hline DIWANIYA & $-3.01 /$ (Dec. 1998) & 52.13 & -0.001 (Oct. 2000) & $-31.42 /$ (Jan. 2007-Nov.2009) \\
\hline NASIRIYA & $-3.07 /$ (Dec. 1990) & 50.00 & $-0.06 /$ (Mar. 1991) & $-29.04 /$ (Dec. 2007-Sept. 2010) \\
\hline BASRA & $-3.48 /$ (Dec. 1998) & 42.55 & -0.001 (Sept. 1995) & -31.86 (Jan.2008-Nov.2009) \\
\hline
\end{tabular}

Table-3 summarize the frequency of each wet / drought conditions for all stations. The results showed that the Mild wet / drought (Extremely wet /drought) conditions are the highest (lowest) number of wet / drought event than other conditions for all stations. In drought condition, the highest (lowest) number of drought events occurred in Diwaniya and Nasiriya (Basra, Kirkuk, and Baghdad) (the number of drought events between 188-196 (160-163) times). Sinjar (Tel Affar) recorded the highest numbers of moderately (severely) drought events, while the highest numbers of extremely drought events existed in the Mosul and Tel Affar.

Table-3 the numbers of wet / drought event results for the RDI 9-months.

\begin{tabular}{|c|c|c|c|c|c|c|c|c|}
\hline Station & E.W & S.W & Mo.W & Mi.W & Mi.D & Mo.D & S.D & E.D \\
\hline MOSUL & 4 & 15 & 32 & 156 & 112 & 20 & 19 & 18 \\
\hline SINJAR & 2 & 16 & 33 & 155 & 101 & 36 & 22 & 11 \\
\hline TEL AFFAR & 7 & 6 & 28 & 186 & 85 & 16 & 29 & 19 \\
\hline KIRKUK & 1 & 12 & 44 & 158 & 104 & 23 & 17 & 17 \\
\hline BAGHDAD & 1 & 11 & 45 & 156 & 101 & 29 & 23 & 10 \\
\hline RUTBA & 9 & 13 & 23 & 165 & 111 & 27 & 14 & 14 \\
\hline HAI & 0 & 14 & 47 & 137 & 117 & 35 & 14 & 12 \\
\hline DIWANIYA & 3 & 24 & 41 & 112 & 144 & 28 & 15 & 9 \\
\hline NASIRIYA & 0 & 20 & 41 & 127 & 136 & 23 & 16 & 13 \\
\hline BASRA & 5 & 14 & 31 & 166 & 102 & 26 & 16 & 16 \\
\hline
\end{tabular}



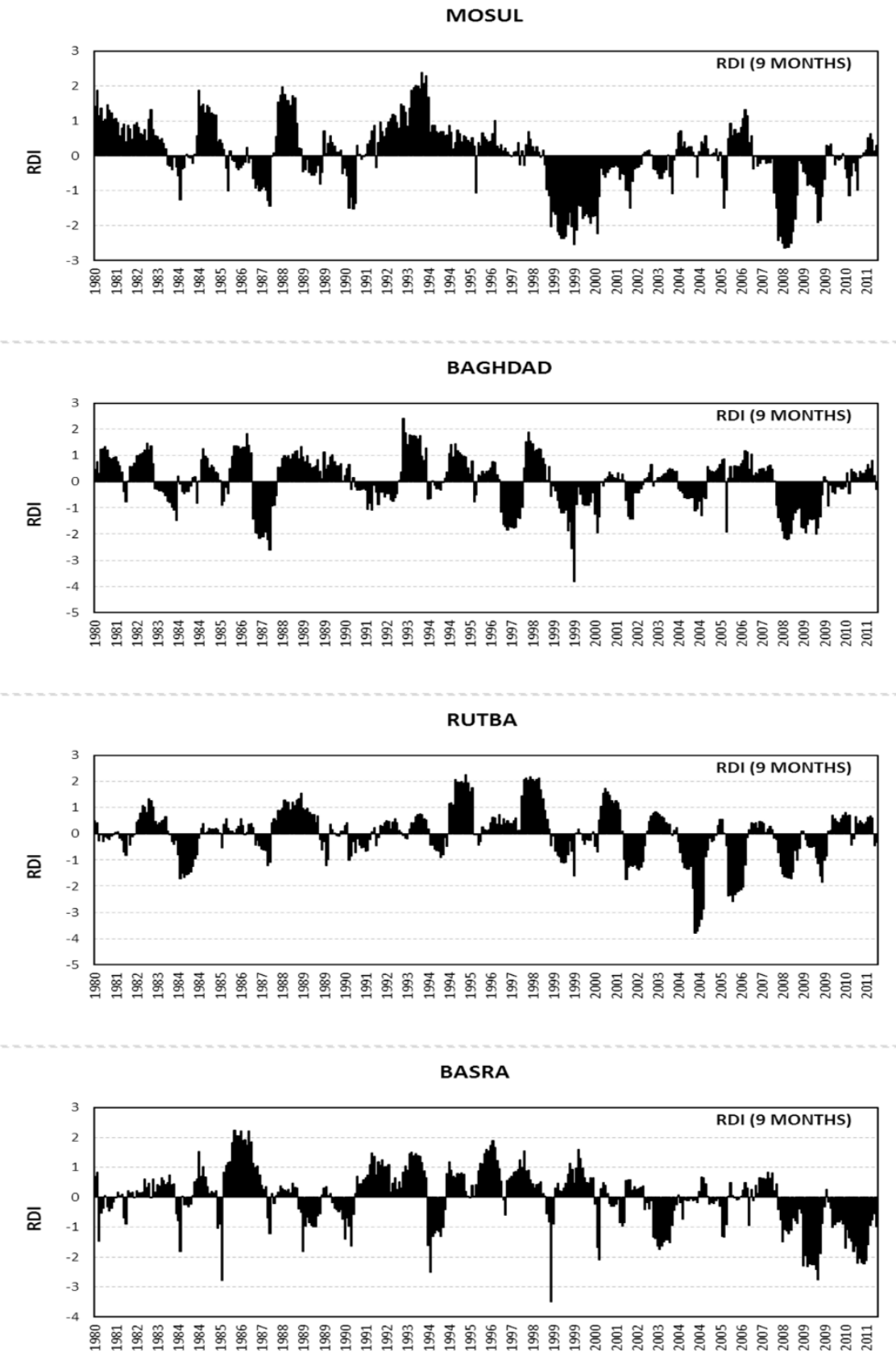

Fig 2:- The time series of RDI for some stations. 
The duration of period (30) years was divided into three period each period represents by ten years. The percentage of drought events at three periods for all stations was calculated as shown in Fig.3. It was observed that the last period had the maximum percentage of drought events for all stations as compared with the previous periods except three stations. Indeed, the Kirkuk and Basra experienced the higher value of drought event at the first period, while the Nasiriya station exposed to the stronger drought at second period.

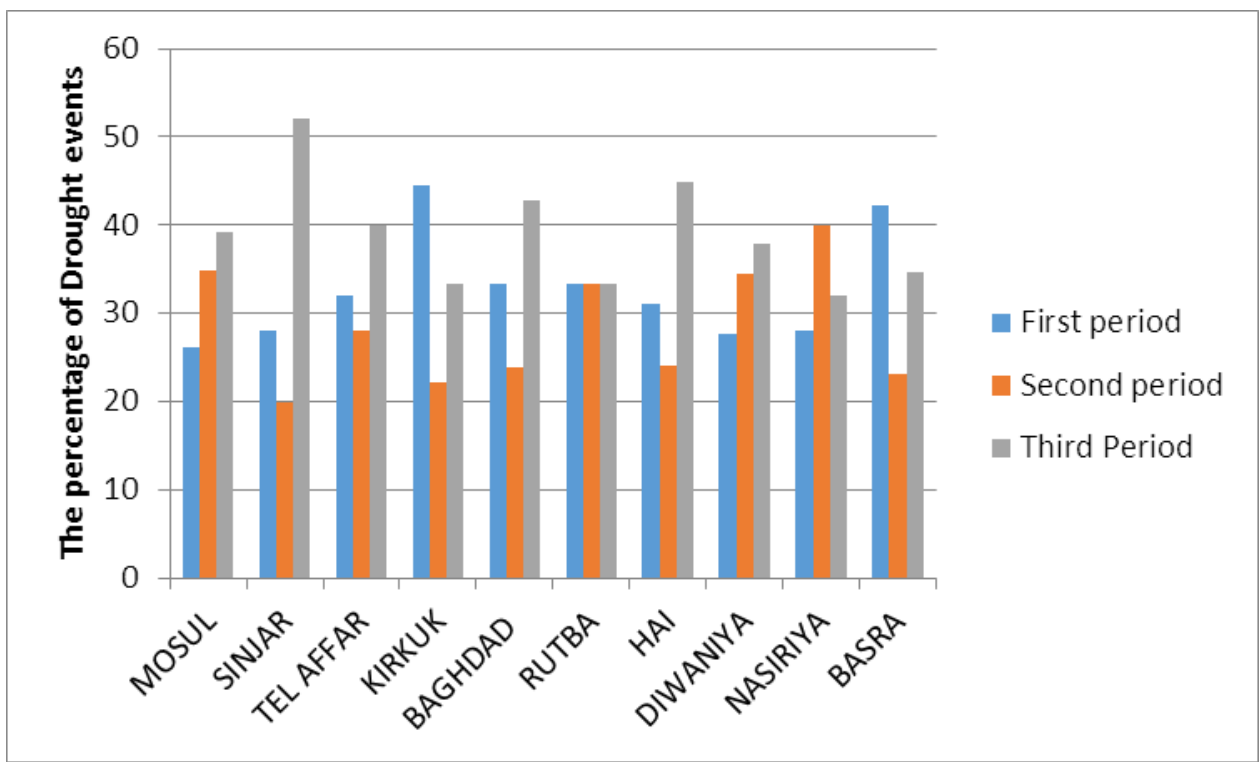

Fig 3:- the percentage of drought events for all stations at three periods.

The RDI characteristics were used to generate drought maps for Iraq region using GIS software as shown in Fig.3. The spatial pattern of the average duration of drought (Davg) shows an increasing trend from eastern part toward southwestern of the Iraq region, ranged from 2.62 to 10 . The spatial distribution of the average severity of drought (Savg) ranged from -2.12 to -7.87 . The highest value of the average severity of drought (Savg) dominated in the central Iraq decreases toward northeastern, and southwest of the study area. It can be seen from figure the Baghdad and Nasirya regions experienced the highest magnitude droughts and had the longer durations as compared with other regions.
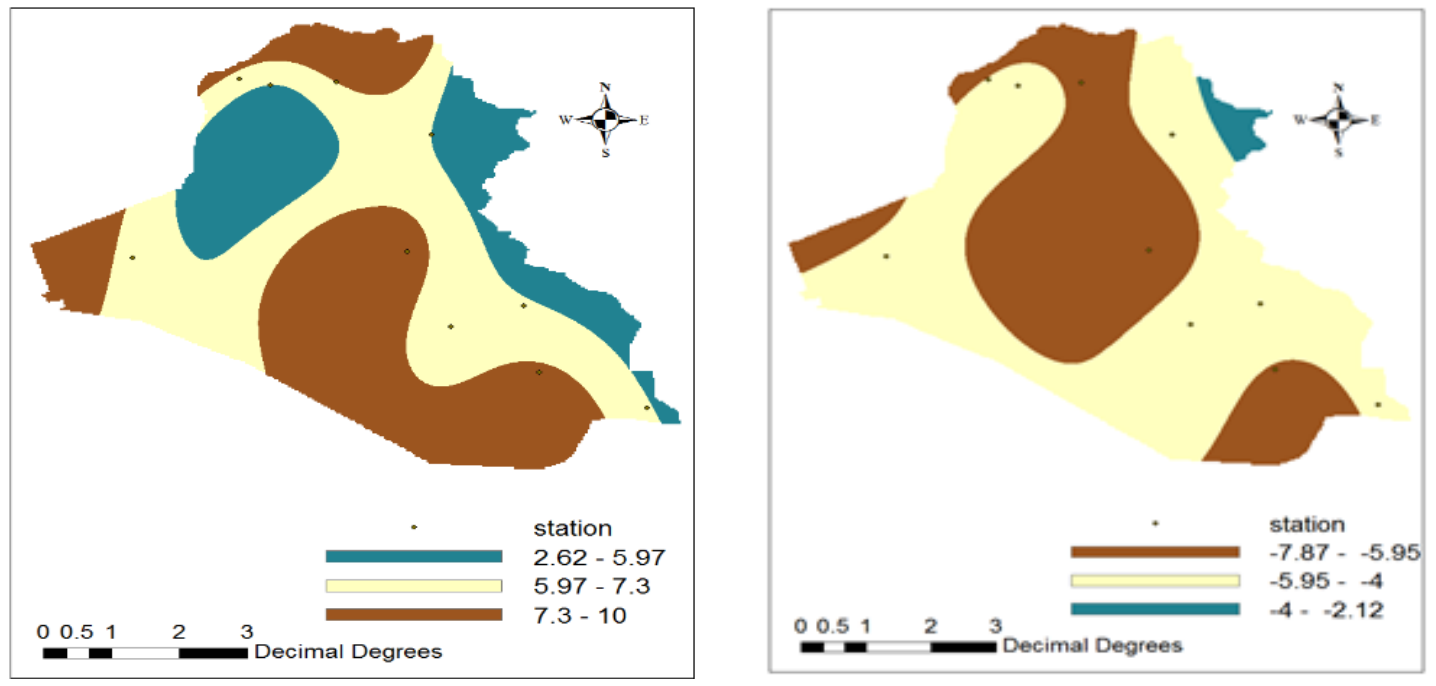

Fig 4:- The Davg and Savg drought using RDI. 


\section{Conclusion:-}

The aim of this study is to analyze the drought characteristics in Iraq region. The Reconnaissance Drought Index (RDI) was used to analyze the drought based on the historical data for ten meteorological stations during the years from 1980 to 2011. The results showed that the 2008 year was the worst drought years had passed in all parts of Iraq, which was consistent with the finding of [9] and [12]. It was found that the frequency of each wet / drought conditions indicated that the Mild wet / drought (Extremely wet /drought) conditions are the highest (lowest) number of wet / drought event than other conditions for all stations. Also, most study regions were exposed to the highest drought events during the period from 1999 to 2009. As spatial pattern results, the Baghdad and Nasirya regions experienced the highest magnitude droughts and had the longer durations as compared with other regions through the study period.

\section{References:-}

1. Dalby, S. "Climate geopolitics: Securing the global economy." International Politics 52.4 (2015): 426-444.

2. Palmer, W.C. Meteorological drought. Vol. 30. Washington, DC: US Department of Commerce, Weather Bureau, 1965.

3. Gibbs, W.J. and Maher, J.V. Rainfall Deciles as Drought Indicators, Bureau of Meteorology bulletin No. 48 . Commonwealth of Australia: Melbourne; 1967,29.

4. Brown, T.J. and Kangas, R.S. Characteristics of US drought and pluvials from a high-resolution spatial dataset. International Journal of Climatology, 2007, 27,1303e1325.

5. McKee, T.B., Doeskin, N.J. and Kleist, J. The relationship of drought frequency and duration to time scales. In: 8th Conference on Applied Climatology. American Meteorological Society, 1997, pp. 179e184.

6. Tsakiris, G. and Vangelis, H. Establishing a drought index incorporating evapotranspiration. Eur Water (9/10), 2005,3-11.

7. Vicente-Serrano, S. M., Begueria, S. and Lopez-Moreno, J. I. A multi-scalar drought index sensitive to global warming: The Standardized Precipitation Evapotranspiration Index. Journal of Climate 23: 2010, 1696 - 1718.

8. Pashiardis, S. and Michaelides, S. Implementation of the Standardized Precipitation Index (SPI) and the Reconnaissance Drought Index (RDI) for regional drought assessment: a case study for Cyprus. European Water, 23(24), 2008, 57-65.

9. Al-Timimi, Yaseen K., and Monim H. Al-Jiboori. "Assessment of spatial and temporal drought in Iraq during the period 1980-2010." Int J Energy Environ 4.2 (2013): 291-302.

10. Khalili, D., Farnoud, T., Jamshidi, H., Kamgar-Haghighi, A. A. and Zand-Parsa, S. Comparability analyses of the SPI and RDI meteorological drought indices in different climatic zones. Water resources management, 25(6), 2011, 1737-1757.

11. Rasheed, A. M. M. Analysis of rainfall drought periods in the North of Iraq using standard precipitation index (SPI). Al Rafidain Eng. J, 18, 2010,60-72.

12. Mahmood Agha, O.M.A., and Şarlak, N. Spatial and temporal analysis of droughts in Iraq using the Standardized Precipitation Index. IOSR Journal of Applied Physics, 8,(6), 2016, 19-25.

13. Tsakiris, G., Loukas, A., Pangalou, D., Vangelis, H., Tigkas, D., Rossi, G. and Cancelliere, A. Drought characterization [Part 1. Components of drought planning. 1.3 .Methodological component].2007 85-102.

14. Frank, A. B. Evapotranspiration from Northern Semiarid Grasslands, Agron. J., 95(6), 2003,1504-1509.

15. DehghaniSanij, H., Yamamoto, T., and Rasiah, V.: Assessment of evapotranspiration estimation models for use in semi-arid environments, Agr. Water Manage., 64(2), 91-106, 2004.

16. Kurc, S. A. and Small, E. E.: Dynamics of evapotranspiration in semiarid grassland and shrubland ecosystems during the summer monsoon season, central New Mexico, Water Resour. Res., 40(9), W0930501-W0930515, 2004.

17. Allen, R. G., Pereira, L. S., Raes, D., \& Smith, M. (1998). Crop evapotranspiration-Guidelines for computing crop water requirements-FAO Irrigation and drainage paper 56. FAO, Rome, 300(9), D05109 